\title{
Misdevelopments, Pathologies, and Normative Revolutions: Normative Reconstruction as Method of Critical Theory
}

\author{
JÖRG SCHAUB \\ School of Philosophy and Art History, University of Essex, UK
}

In this article I argue that the method of normative reconstruction underlying Freedom's Right undermines Critical Theory's aspiration to be a force that is unreservedly critical and progressive. I start out by giving a brief account of the four premises of the method of normative reconstruction and unpack their implications for how Honneth conceptualizes social pathologies and misdevelopments, specifically that these notions are no longer linked to radical critique and normative revolution. In the second part, I demonstrate that abandoning forms of radical critique and normative revolution is internally linked to adopting this method, before arguing that Freedom's Right contains no resources to account for why abandoning them does not amount to a deficiency. In the final part, I point out two problematic implications of turning away from radical critique and normative revolution for the very project Honneth pursues in Freedom's Right. I show that Honneth's own view about the limited scope of application of the method of normative reconstruction and his account of the dangers associated with social misdevelopments give us (additional) reasons to consider this method to be incomplete. Finally, I contend that the explanatory power of Freedom's Right is dubious because methodological premises that form part of normative reconstruction lead Honneth to ignore relevant alternative explanations of processes of deviation and disassociation from norms of social freedom, which he characterizes as social misdevelopments.

KEYWORDS Axel Honneth, Critical Theory, normative reconstruction, social pathology, normative revolution, internal vs. radical critique 


\section{Introduction}

Some of the most prominent figures in contemporary Frankfurt School Critical Theory like Jürgen Habermas and Axel Honneth have adopted normativereconstructive methods. In Freedom's Right, Honneth presents a new and distinct approach to "normative reconstruction." I This magnum opus on "The Social Foundations of Democratic Life" stands in the tradition of Frankfurt School Critical Theory as it assigns a central role to the notions of social pathology and social misdevelopments. Honneth is adamant that these notions set apart the Frankfurt School tradition from other approaches to moral and political philosophy. ${ }^{2}$ The method of normative reconstruction outlined in Freedom's Right is therefore meant to be a method for Critical Theory. For this reason, it is legitimate to criticize this method for not being compatible with the aims of Frankfurt School Critical Theory.

In this article, I examine the method of normative reconstruction as re-conceived by Honneth in Freedom's Right, and show that it is ill-suited for taking Critical Theory forward. I argue that in certain respects it amounts to a step backwards compared to works from Honneth's middle period, such as Redistribution or Recognition ? $^{3}$ For critical theorists should make room for forms of radical critique and normative revolutions as well as avoid focussing exclusively on those norms that are already underlying existing, reproductively relevant institutions.

A normative revolution takes place, according to Honneth, if reproductively relevant social institutions as well as the norms underlying them are replaced by different social institutions in which new norms are operative. Honneth gives the example of the transition from the "estate-based order of pre-modern society" to the modern "bourgeois-capitalist society." 4 This transition involved a process in which the "pre-modern concept of honor" is abandoned and the void is then filled by a "democratized" notion of equal legal respect and a "meritocratized" notion of esteem that tracks a person's contributions to society. ${ }^{5}$ In the wake of this process, institutions in which the norm of legal equality was operative replaced institutions of "legal recognition" that were grounded in "origin, age, or function." 6 Since this transition "led to the establishment of two completely different spheres of recognition," Honneth speaks of a "transformation" that is "indeed revolutionary." 7

Radical critique refers to all forms of critique that invoke norms that are not (yet) underlying existing, reproductively relevant social institutions.

\footnotetext{
${ }^{I}$ A. Honneth, Freedom's Right: The Social Foundations of Democratic Life, trans. J. Ganahl (Cambridge: Polity, 20I4). Throughout this paper I mean by "normative reconstruction" specifically the method outlined in Freedom's Right, not any method that might be described in these terms.

${ }^{2}$ See A. Honneth, "Pathologies of the Social: The Past and Present of Social Philosophy," in his Disrespect: The Normative Foundations of Critical Theory (Cambridge: Polity, 2007), 3-48; and "A Social Pathology of Reason: On the Intellectual Legacy of Critical Theory," in his Pathologies of Reason: On the Legacy of Critical Theory, trans. J. Ingram (New York, NJ: Columbia University Press, 2009), I9-42.

3 See A. Honneth, "Redistribution as Recognition: A Response to Nancy Fraser," in Redistribution or Recognition? A Political-Philosophical Exchange, N. Fraser and A. Honneth (New York: Verso, 2003), I I0-97.

${ }^{4}$ Honneth, "Redistribution as Recognition," I 38.

5 Honneth, "Redistribution as Recognition," I4I.

${ }^{6}$ Honneth, "Redistribution as Recognition," I 4 I.

7 Honneth, "Redistribution as Recognition," I4 I; my emphasis.
} 
Honneth provides an example of radical critique in Freedom's Right: a "great number of organized workers" in the first half of the twentieth century were radically critical of the capitalist market since they were criticizing it in terms of norms that were not operative in reproductively relevant institutions of productive social cooperation. ${ }^{8}$

Honneth is adamant that a "revolution in the recognition order" presupposes forms of radical critique, that is, forms of thinking that involve new norms that are invoked to delegitimize existing, reproductively relevant institutions and to legitimize the establishing of new social institutions. ${ }^{9}$ In the case of the transition from the pre-modern estate-based society to the modern capitalist social order, Honneth refers to such forms of radical critique when he talks about a "rise of posttraditional ways of thinking" that paved the way for this normative revolution. ${ }^{\text {Io }}$

This article presents a critique of the method of normative reconstruction, as outlined in Freedom's Right, since it is, at least in its current form, not suited to advance Critical Theory, given Critical Theory's aspiration to be a force that is unreservedly critical and progressive. I make this point by reading (the middle period) Honneth against (the latest) Honneth since I take the notions of normative revolution and radical critique from Honneth himself. The upshot of my argument is that Critical Theory requires a method that, unlike normative reconstruction, remains open to the possibility of normative revolutions and does not turn its back on radical critique. ${ }^{\text {II }}$

I start out by giving a brief account of the four premises of the method of normative reconstruction. In doing this, I point out the ways in which normative reconstruction is different from other forms of internal critique and explain why adopting normative reconstruction implies abandoning radical critique and normative revolutions. I then unpack the implications of the premises of normative reconstruction for how Honneth re-conceptualizes social pathologies and misdevelopments in Freedom's Right, specifically that these notions are no longer linked to radical critique and normative revolution (I). In the second part, I highlight that it is surprising that Honneth adopts in Freedom's Right a method that limits this approach to Critical Theory to promoting gradual progress. For in Redistribution or Recognition? Honneth was alive to the fact that gradual progress is only one way in which progress can take place (II.I). In response, one could argue

\footnotetext{
${ }^{8}$ Honneth, Freedom's Right, 2 Io. Honneth acknowledges that a significant part of the "labour movement" was not in any obvious way "dealing with the principle of the reformability" of the capitalist market, but aimed for "an entirely different model” (Honneth, Freedom's Right, 210).

9 Honneth, "Redistribution as Recognition," I 43; my emphasis, see also I40.

Io Honneth, "Redistribution as Recognition," I40.

${ }^{\text {II }}$ For the purposes of this paper, I am agnostic with regards to whether Critical Theory should rely on internal or external critique. The point I am making is that Critical Theory requires a methodology that remains open to radical critique and normative revolution. I therefore do not criticize Honneth for embracing internal critique, but for embracing a particular version of internal critique in Freedom's Right that severs Critical Theory's link with radical critique and normative revolution. Honneth's reasons to embrace internal critique will therefore not be scrutinized in this article. Honneth is of the opinion that social criticism ought to be "anchored in the social practices of a given society," for otherwise it is difficult to account for where the norms informing social criticisms come from, and why they can be assumed to be motivationally effective (A. Honneth, "Reconstructive Social Criticism with a Genealogical Proviso," in his Pathologies of Reason: On the Legacy of Critical Theory (New York, NJ: Columbia University Press, 2009), 43-63, at 47; see also Freedom's Right, 337-38 n. 6).
} 
that abandoning radical critique and revolutionary progress does not amount to a deficiency. Indeed, while Honneth does not directly argue this, what he says in Freedom's Right about historical progress can be reconstructed as a defence of his method against this worry. I show why this reconstructed defence is unconvincing (II.2). In the final part, I point out two problematic implications of the premises that make up the method of normative reconstruction for the project Honneth pursues in Freedom's Right (III). I show that Honneth's own view about the limited scope of application of the method of normative reconstruction and his account of the dangers associated with social misdevelopments give us (additional) reasons to consider this method to be incomplete (III.I). Finally, I contend that the explanatory power of Freedom's Right is dubious because methodological premises that form part of normative reconstruction lead Honneth to ignore relevant alternative explanations of processes of deviation and disassociation from norms of social freedom, which he characterizes as social misdevelopments (III.2).

\section{The method of normative reconstruction}

The method of "normative reconstruction" underpins Honneth's new approach to the theory of justice and Critical Theory. His account of it is surprisingly short. ${ }^{\mathrm{I} 2}$ Honneth also does not demonstrate that this method is compatible with core tenets of Frankfurt School Critical Theory, or superior to alternative approaches to Critical Theory. ${ }^{\mathrm{I} 3}$

What Honneth does say is that the method of normative reconstruction is comprised of four premises. Like Honneth, I will use the term "normative reconstruction" to refer to the distinct method outlined in Freedom's Right that is made up of these four premises. ${ }^{\mathrm{I} 4}$

The first premise of normative reconstruction is the premise of "normative social integration."I5 Honneth assumes that social institutions that are relevant for the reproduction of society "are ultimately regulated by norms that are ethical in the sense that they embody conceptions of shared goods." ${ }^{6}$ From this premise Honneth infers that "social orders, without exception, must legitimate themselves in the light of ethical values and ideals that are worth striving for" in the eyes of the members of that society. ${ }^{17}$

\footnotetext{
${ }^{12}$ See Honneth, Freedom's Right, I-I I.

${ }^{13}$ There are brief discussions of the limits of Rainer Forst's (Honneth, Freedom's Right, 98, 337-38 n. 6) and Habermas's (Honneth, Freedom's Right, 3, 35, 64, 280, 282) approach. I come back to the former in section II.2 below. As for the latter, Habermas confines himself to a normative reconstruction of "the development of the constitutional state" (Honneth, Freedom's Right, 345 n. I). See J. Habermas, Between Facts and Norms: Contributions to a Discourse Theory of Law and Democracy, trans. W. Rehg (Cambridge: Polity, I996), 64ff. Honneth insists that if the aim is to give an account of the actuality of social freedom in modern societies, then one has to reconstruct a range of different social spheres - not just constitutional law, but also the market and social practices of a personal nature - and take into account how these spheres interact (Honneth, Freedom's Right, 332).

${ }^{14}$ Honneth concedes that his methodological "premises ... cannot be so easily justified in advance, rather they can only be revealed in the course of the investigation" (Honneth, Freedom's Right, 3). I agree, but this does not change the fact that in Freedom's Right Honneth does not do enough to scrutinize some of his methodological premises. See Sections III.2 and III.3.

${ }^{15}$ Honneth, Freedom's Right, 4.

${ }^{16}$ Honneth, Freedom's Right, Io.

${ }^{17}$ Honneth, Freedom's Right, 4 .
} 
The second premise has to be understood in connection with Honneth's attempt to outline an approach to the theory of justice that proceeds by way of an "analysis of society." ${ }^{8} \mathrm{He}$ argues that our notions of justice depend on and "cannot be understood in isolation from" shared ethical values that are already underlying existing institutions that are relevant for social reproduction. ${ }^{19}$ However, Honneth makes it clear that not any ethical ideal that is institutionalized, reproductively relevant, and informs what members of society regard as just can become the object of normative reconstruction. Only those "values" underlying reproductively relevant social institutions can become the subject matter of this method that are "normatively superior to historically antecedent social ideals."

The third premise pertains to how normative reconstruction categorizes the elements of social reality and identifies those institutions it needs to reconstruct: "Out of the diversity of social reality" we are supposed to select "those institutions and practices that are truly capable of securing and realizing general values." ${ }^{2}$

The final premise is of particular relevance for my purposes as it concerns the critical dimension of Honneth's project. "Reconstructive criticism" denotes a specific form of internal critique: it ensures that normative reconstruction does not "merely affirm existing instances of ethical life," for it is supposed to reveal "the extent to which ethical institutions and practices do not represent the general values they embody in a sufficiently comprehensive or complete fashion."22

The subject matter of my critique is the method of normative reconstruction, not internal critique in general. Reconstructive criticism interacts with the other premises of the method of normative reconstruction and constitutes a particular form of internal critique that is in many respects unlike other forms of internal critique: first, reconstructive criticism entails a commitment to the particular norms that are underlying already existing, reproductively relevant institutions, since all it does is to assess whether these "ethical institutions and practices" could realize the "values they embody" in a more "comprehensive or complete fashion." ${ }^{3}$ Other forms of internal critique do not entail such a commitment to the norms already underlying existing institutions. These forms of internal critique thus differ from reconstructive criticism in that they might call for a normative revolution, that is, new norms and institutions, if it turns out that established institutions and the norms underlying them are fundamentally inconsistent or defective. Second, the only kind of progress that normative reconstruction promotes is "gradual" progress because "given practices" are only criticized for not realizing ethical values that are already operative in these institutions in a "better, more perfect or comprehensive way" ${ }^{24}$ whereas other forms of internal critique can, as we have just seen, promote revolutionary progress.

\footnotetext{
${ }^{18}$ Honneth, Freedom's Right, II.

19 Honneth, Freedom's Right, Io, also 4-5.

${ }^{20}$ Honneth, Freedom's Right, 5, also 63-4.

${ }^{21}$ Honneth, Freedom's Right, Io, also I 6.

${ }_{22}$ Honneth, Freedom's Right, ro, translation amended; also 9.

${ }^{23}$ Honneth, Freedom's Right, Io, translation amended.

${ }^{24}$ Honneth, Freedom's Right, 9.
} 
There are further differences between reconstructive criticism and other forms of internal critique. For instance, reconstructive criticism interacts with the third premise, according to which those "institutions and practices" that are reconstructed "are truly capable of securing and realizing general values." 25 Other versions of internal critique do not make it a methodological premise that the institutions they are concerned with are capable of realizing the norms that are underlying them. In contrast with normative reconstruction, these forms of internal critique are therefore open to the possibility that existing, reproductively relevant institutions are unable to realize the norms that are (allegedly) operative in them. Finally, normative reconstruction is much more limited in scope compared to other versions of internal critique. One of the premises of normative reconstruction states that only norms that are already underlying existing, reproductively relevant social institutions can become the subject matter of normative reconstruction and, by implication, of reconstructive criticism; ${ }^{26}$ other forms of internal critique are, unlike normative reconstruction, open to reconstruct, for instance, the norms informing counter-practices that are driven by negative experiences people have with the norms that are realized by established, reproductively relevant social institutions. A case in point is the radically critical "labour movement" that was not in any obvious way "dealing with the principle of the reformability" of the capitalist market, but aimed for "an entirely different model." 27

The premises of normative reconstruction also have important implications for how Honneth re-conceives of social aberrations in Freedom's Right, namely, as failures to realize norms that are already operative in social institutions in a "better" or "more ... comprehensive" fashion. ${ }^{28}$ This involves a shift from his earlier work on social aberrations. Honneth operates in Freedom's Right with a new distinction, which we need to briefly review as it plays a role in the later argument. ${ }^{29}$

In Freedom's Right Honneth distinguishes between two types of relationships of recognition: those associated with individual freedom (e.g. legal and moral freedom) and those associated with social freedom (e.g. personal, economic and political relationships). Both concern practices in which participants "ascribe each other a certain status in light of a shared norm - a status that entitles them to the consideration shown them by other subjects." ${ }^{\circ}$ In the case of individual freedom "norms of recognition 'regulate' actions in a way that ensures intersubjective coordination." ${ }^{3}$ F For example, being recognized as a subject of rights enables me to reject discursive demands and to make it impossible for others to interfere with a permitted course of action. However, acting on the norms of individual freedom "does not itself serve to realize ... aims." ${ }^{22}$ For instance, noninterference does not

\footnotetext{
${ }_{25}$ Honneth, Freedom's Right, io, also I6.

26 See Honneth, Freedom's Right, 3-4.

27 Honneth, Freedom's Right, 2 Io.

${ }^{28}$ Honneth, Freedom's Right, 9.

29 For a critical account of the development of Honneth's thoughts on the notion of social pathology, see F. Freyenhagen, "Honneth on Social Pathologies: A Critique," Critical Horizons, this issue.

${ }^{\circ}$ Honneth, Freedom's Right, I 24.

${ }^{31}$ Honneth, Freedom's Right, I 25.

${ }^{32}$ Honneth, Freedom's Right, I24.
} 
suffice for achieving whatever I want to achieve with my actions. For this reason, individual freedom is freedom in the modus of possibility.

This sets apart individual freedom from social freedom. In the latter case, norms of recognition "constitute' a kind of action that the subjects involved can only carry out cooperatively"; ${ }^{33}$ and the parties involved realize their aims by acting on the norms of recognition. Social freedom therefore involves a complementarity: it "refers to the reciprocal experience of seeing ourselves confirmed in the desires and aims of the other, because the other's existence" is recognized as "a condition for fulfilling one's own desires and aims." 34 The market sphere is thus a sphere of social freedom if the subjects who encounter each other are affirming each other's aims because they are alive to the fact that their aims supplement each other in the sense that the other fulfilling their aim is a precondition of me fulfilling mine, and vice versa. ${ }^{35} \mathrm{My}$ aim is realized through interactions of this type. Social freedom is therefore freedom in the modus of actuality.

Honneth associates different types of social aberrations with the two types of relationships of recognition. Social pathologies are presented as aberrations related to relationships of individual freedom, whereas social misdevelopments denote aberrations of social freedom. Both forms of aberrations are characterized as socially caused misunderstandings of the norms that are already underlying existing, reproductively relevant social practices, which, in turn, lead to a failure to realize the norms underlying them more adequately. ${ }^{36}$ For this reason, the link between both forms of social aberrations, on the one hand, and radical critique and normative revolution, on the other hand, is severed.

"Social pathologies of legal and moral freedom represent social embodiments of misinterpretations for which the rules of action themselves are at least partially responsible," 37 whereas in the case of social misdevelopments their source "must be sought elsewhere, not in the constitutive rules of the respective system of action." 38 Let me give you an example for each: the socially triggered tendency to withdraw from communicative relationships and to view one's involvements with others almost exclusively from the impersonal standpoint of law is one of Honneth's examples of a legal pathology. Think, for instance, of a husband who, anticipating his divorce, starts to evaluate each and every move he makes strategically according to how it will be evaluated by a judge who has to decide on the custody of the couple's children. ${ }^{39}$ The deregulation of the market sphere can serve as an example of a social misdevelopment. For it leads to a situation in which interactions between individuals are less and less about general and reciprocal interest satisfaction. ${ }^{40}$

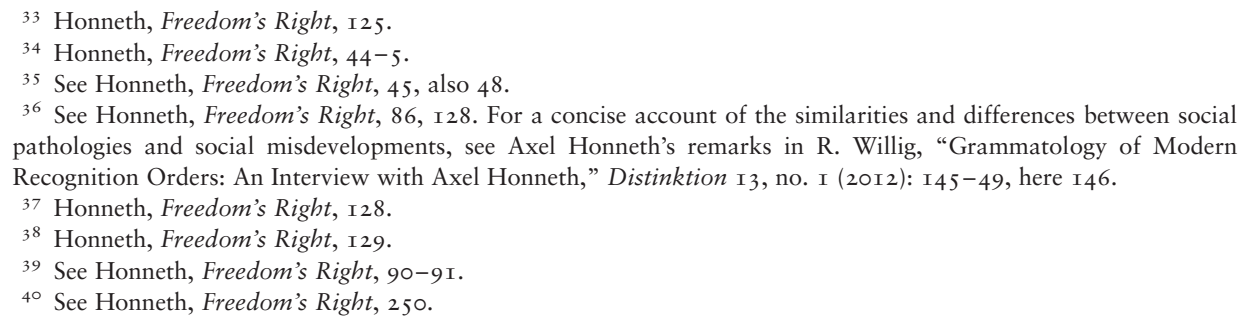




\section{Critical Theory without radical critique and revolutionary progress}

In the previous section, I have explained why adopting the method of normative reconstruction implies turning away from radical forms of critique and normative revolution. As a consequence, the only kind of progress that the method of normative reconstruction fosters is a form of gradual progress. This is because normative reconstruction is exclusively concerned with how norms that are already operative in reproductively relevant institutions can be realized in a "better, more perfect or comprehensive way." ${ }^{\mathrm{I}}$

The fact that Honneth argues in Freedom's Right for a method for Critical Theory that limits Critical Theory to promoting gradual progress comes as a surprise. For Honneth made it clear in his previous works that gradual progress constitutes only one way in which progress can take place. ${ }^{42}$

\section{1. Two types of progress}

The gradual type of progress that forms part of Freedom's Right is driven by struggles for recognition that are triggered by the "surplus of validity" that "each principle of recognition has" and which sets "in motion" a "moral dialectic between the universal and the particular." 43 By invoking a "universal principles of recognition (love, respect, achievement)" people make "claims related to a particular aspect (need, life-situation, contribution) which has not yet found appropriate consideration." 44 The first type of progress is therefore about more adequate interpretations and/or more comprehensive implementations of already established norms of recognition. A case in point is the campaign for gay marriage where the universal principle of legal equality is invoked to insist on the possibility for gay couples to acquire a legal status that was originally defined without taking non-heterosexual couples into consideration.

In Redistribution or Recognition?, Honneth refers to the second type of progress that is absent from Freedom's Right as a "revolution in the recognition order." 45 Revolutionary progress has to be distinguished from gradual progress because in the former case we are not dealing with processes that lead to a more adequate interpretation and comprehensive realization of norms already underlying existing, reproductively relevant social institutions. Rather, norms that are operative in reproductively relevant social institutions are abandoned in a normative revolution and different norm-institution complexes, that is, new institutions with new underlying norms, are established in the void left behind. Progress here is not gradual. Honneth's paradigm example of a normative revolution that has raised the level of normative social integration is the transition from the pre-modern estatebased society to the modern bourgeois capitalist society. ${ }^{46}$ As part of this

\footnotetext{
${ }^{4}$ I Honneth, Freedom's Right, 9 .

${ }^{42}$ Honneth, "Redistribution as Recognition," I74. Also A. Honneth, “The Normativity of Ethical Life," Philosophy and Social Criticism (forthcoming).

${ }^{43}$ Honneth, "Redistribution as Recognition," I 86; translation amended. Also A. Honneth, "Grounding Recognition:

A Rejoinder to Critical Questions," Inquiry 45, no. 4 (2002): 499-5I9, here 5 I7.

44 Honneth, "Redistribution as Recognition," I 86; translation amended.

45 "Redistribution as Recognition," I43; my emphasis, see also I40.

${ }^{46}$ Honneth, "Redistribution as Recognition," I $38-50$.
} 
revolution, the "pre-modern concept of honor" is abandoned and replaced by a "democratized" notion of equal respect and a "meritocratized" notion of esteem that tracks a person's contributions to society. ${ }^{47}$ What is crucial is that neither of the two new norms of recognition can be understood as a more adequate interpretation of the "pre-modern concept of honor."

Honneth's view on progress in Redistribution or Recognition? can therefore be summarized as follows: in addition to gradual progress there is revolutionary progress. Revolutionary progress can raise the level of normative social integration, and has to be accompanied by forms of radical critique. For a normative revolution presupposes that existing, reproductively relevant social institutions are challenged with reference to norms that are not yet operative in these reproductively relevant institutions.

\section{2. Is abandoning normative revolution and radical critique a fault?}

Given Honneth's belief that revolutionary progress is possible and that it presupposes radical critique, the question arises why he does not think that it amounts to a deficiency of the method of normative reconstruction that it turns its back on normative revolution and radical critique. Honneth does not defend normative reconstruction directly against this worry. The purpose of this section is therefore to identify those resources in Freedom's Right that Honneth could draw on in order to support his view that abandoning normative revolution and radical critique is not a shortcoming. The most promising candidate for such a reply is Honneth's account of historical progress. I will scrutinize this account in form of reconstructed replies and show that none of them is ultimately convincing.

\section{2. a. Social reproduction and progress}

One line of defence that is available to Honneth consists in combining the premise of "normative social integration" and one aspect of the second premise: Honneth maintains that one has to show that the established "social ideals" ${ }^{8}$ that become the object of normative reconstruction "are not only socially but also morally valid." 49 For him, this requires to demonstrate that these established values are "normatively superior to" those realized in "historically antecedent" normative orders. ${ }^{50}$ Therefore normative reconstruction is "only possible" if it entails a procedure to conduct such a "normative comparison." ${ }_{5 \mathrm{I}}$

Against this backdrop, we can ascribe to Honneth the following view: normativereconstructive Critical Theory does not need to concern itself with radical critique or normative revolutions because normative reconstruction pertains only to societies whose reproductively relevant norm-institution complexes are, from a backward looking perspective, the normatively most advanced.

There are two problems with this argument. First, the resources Freedom's Right encompasses to make a case for the historical superiority of the liberal-capitalist do

\footnotetext{
47 Honneth, "Redistribution as Recognition," I4I.

${ }^{4}{ }^{8}$ Honneth, Freedom's Right, 4, also Io.

49 Honneth, Freedom's Right, 64.

${ }^{5}$ Honneth, Freedom's Right, 5 .

${ }^{51}$ Honneth, Freedom's Right, 63-4.
} 
not add up to a convincing argument. Second, and more importantly, even if he succeeded to show that the liberal-capitalist order is normatively superior in this backward looking sense, this would still not suffice to demonstrate the irrelevance of radical critique and normative revolution. I will deal with both problems in turn.

Honneth's " "transcendental' interpretation of ... historical progress" can be read as an attempt to underpin the alleged historical superiority of the liberalcapitalist social order. ${ }^{52}$ This "transcendental' interpretation" rests on the assumption that the "fact that subjects actively preserve and reproduce freedomguaranteeing [freiheitsverbürgende] institutions is theoretical evidence of their historical value." 53

Since it is not entirely clear what Honneth has in mind when he refers to "freedom-guaranteeing institutions," I will distinguish a strong from a weak reading of this argument and show that neither is fit for purpose.

The strong reading involves the plausible claim that the active participation of subjects in the reproduction of a genuinely free society could be regarded as a vindication of the validity of the norms that are underlying its institutions. For in a genuinely free society acceptance of these norms cannot be the effect of power, that is domination, discipline, inculcation of beliefs and so on. ${ }^{54}$ But simply stating that in a genuinely free society there is a connection between active participation, on the one hand, and the society in question having historical value, on the other hand, does nothing to establish that liberal-capitalist societies are genuinely free societies, as would be required on the strong reading. For this reason, one cannot simply infer from people's participation in liberal-capitalist societies that they are the historically most progressive social formation. Furthermore, one might be worried about a burden of proof that Honneth incurs on the strong reading. He would have to establish that liberal-capitalist societies are genuinely free societies. This, in turn, would require an argument to the effect that we have reached the end of normative-progressive history. Honneth does not present such an argument and it is hard to imagine how it would look. The strong version of the " "transcendental' interpretation of ... historical progress" is therefore, at least in its present form, unconvincing. ${ }^{55}$

According to the weak reading of the argument, participation in any society that protects some basic liberties and is able to reproduce itself without the need to take recourse to excessive brute force shows that this social order is historically superior to all other social formations. This claim does not sit well with one of the core insights of Frankfurt School Critical Theory. ${ }^{56}$ Theorists in this tradition typically deny that we can directly infer from people's active participation in a society that guarantees some basic liberties that it really is legitimate and normatively superior

\footnotetext{
${ }^{2}$ Honneth, Freedom's Right, 59. For a different version of this argument, see A. Honneth, "The Irreducibility of Progress: Kant's Account of the Relationship between Morality and History," in his Pathologies of Reason (New York: Columbia University Press, 2009), I-I8.

53 Honneth, Freedom's Right, 59; translation amended.

${ }^{54}$ See, for example, R. Geuss, The Idea of a Critical Theory: Habermas of the Frankfurt School (Cambridge: Cambridge University Press, I981), 45-54.

55 Honneth, Freedom's Right, 59.

${ }^{56}$ For a similar line of critique see A. Allen, The End of Progress: De-Colonizing Critical Theory (forthcoming).
} 
to prior orders since people might nonetheless be living "in circumstances where they are ... unduly ... pressured, or influenced, in conditions of gross ignorance or false beliefs." 57 For this reason even a liberal political realist like Williams invokes the "Critical Theory Principle" which states that de facto "acceptance of a justification does not count if the acceptance itself is produced by" the "power which is supposedly being justified." ${ }^{8}$ It is, of course, "difficult" to make "good on claims of false consciousness" because it requires "deciding what counts as having been 'produced by' ... power in the relevant sense." 59 But the fact that it is difficult to tell apart genuine acceptance from acceptance that is the effect of power gives us no reason to simply abstract from this possibility. On the contrary, it gives us a reason to turn our attention to the actual "legitimatory mechanisms available in a given society" and the "more subtle forms" of power that are deployed. ${ }^{60}$ In any case, we have no reason to regard active participation in a society that protects some basic liberties as a reliable indicator for it being normatively superior to all social formations preceding it. I have considered this weak reading as it is not ruled out by the ambivalent formulation that Honneth provides, and it constitutes the only straightforward alternative to the strong reading, which itself is tainted with serious problems.

The failure of Honneth's quasi-transcendental arguments is aggravated by the fact that Freedom's Right entails an objection that undermines Honneth's alternative strategy to conduct normative comparisons between recognition orders. Honneth used to invoke two standards to establish progress within and between different recognition orders. The two criteria are: (a) "increases in individuality,"6I that is, "the increase of opportunities to legitimately articulate parts of one's personality"; ${ }^{62}$ and (b) increases in "social inclusion," 63 that is, processes that expand "inclusion of subjects into the circle of full members of society." 64 However, this alternative strategy gives rise to a dilemma. The first horn of the dilemma consists in the fact that standards of this kind (even if they can be shown to be trans-historically and trans-contextually valid) are denounced in Freedom's Right as abstract, empty and useless. This becomes apparent in Honneth's discussion of Rainer Forst's notion of a “right to justification.” If Forst's abstract criterion of "mutual justifiability ... is of little use" and "remains entirely empty," 65 then the same holds true for Honneth's criteria of individuality and inclusiveness since in both cases "determining what counts as" promoting the standard in question "can ultimately only be judged in terms of the ideal actually institutionalized" 66 in a particular social order. This brings me to the second horn

\footnotetext{
57 Geuss, The Idea of a Critical Theory, 50.

$5^{8}$ B. Williams, In the Beginning Was the Deed: Realism and Moralism in Political Argument (Princeton, NJ: Princeton University Press, 2005), 6, see also 82 .

59 Williams, In the Beginning Was the Deed, 6.

60 Williams, In the Beginning Was the Deed, 6; see also R. Geuss, Philosophy and Real Politics (Princeton, NJ: Princeton University Press, 2008), 33.

${ }^{61}$ Honneth, "Grounding Recognition," 5 II .

${ }^{62}$ Honneth, "Redistribution as Recognition," I $84-85$.

${ }^{63}$ Honneth, "Grounding Recognition," 5 I I.

${ }^{64}$ Honneth, "Redistribution as Recognition," I 85.

${ }^{6}$ Honneth, Freedom's Right, 338 n. 6, also 64-6.

${ }^{66}$ Honneth, Freedom's Right, 5; my emphasis.
} 
of the dilemma: if Honneth is correct and we have to draw on the particular interpretations of these standards that are reflected in social institutions that make up a particular social formation, then this amounts to abandoning the aspiration to "adopt a neutral perspective" that would put us in a position to make normative comparisons between normative orders. ${ }^{67}$

Against this backdrop, we can now consider another line of defence that Honneth does not envisage. Instead of arguing that liberal-capitalist societies are genuinely free (as is required by the strong version of the "'transcendental" interpretation of ... historical progress"), Honneth could claim that they realize the most plausible conception of freedom that is historically available. The problem with this rejoinder is that it is not clear what standard Honneth could invoke to support the claim that the liberal-capitalist order realizes the most plausible conception of freedom. For this standard is, according to Honneth, either transhistorical and trans-contextual, but then too abstract and therefore useless; or historical (at least in its interpretation), but then not suitable to underpin normative comparisons between different (historically existing) recognition orders (since these judgements would be at best expressive of how things look to us from within our own recognition order).

In sum, Honneth's arguments for the normative superiority of the liberalcapitalist order fail.

\section{2. b. Progress: backward looking and forward looking}

The difficulties Honneth faces do not end here: even if his comparative arguments were convincing and he succeeded in demonstrating that the liberal-capitalist social order is normatively superior to all past social formations, this still would not suffice to show that radical critique and normative revolution are irrelevant. In order to arrive at this conclusion, Honneth would have to show that forms of critique and dimensions of change that are not grounded in norms that are already underlying reproductively relevant social institutions can be considered "superfluous once we can prove that the prevailing values are normatively superior to historically antecedent social ideals." 68 The reasons why this superfluity-claim rests on a mistake become apparent if we return to Honneth's paradigm example of revolutionary progress.

Let us assume, in line with Honneth's general view of history as a process of cumulative learning, that before the estate-based order was replaced by the liberalcapitalist order, the former was the normatively most advanced social formation. ${ }^{69}$ This means that in the age of the estate-based social order the norms underlying existing institutions could have become the subject matter of normative reconstruction. However, the radically critical work that paved the way for what Honneth considers to be the normatively superior social formation, namely, the liberal-capitalist order, back then fell outside the scope of, and would have been considered irrelevant by, normative-reconstructive Critical Theory since the norms

\footnotetext{
${ }^{67}$ Honneth, Freedom's Right, 5 .

${ }^{68}$ Honneth, Freedom's Right, 5 .

${ }^{69}$ For a concise account of Honneth's understanding of history, see Honneth, "The Normativity of Ethical Life."
} 
now underlying liberal-capitalist institutions were, at that time, not underlying institutions that were relevant for the reproduction of the existing estate-based social order. From the standpoint of normative reconstruction, criticisms of the estate-based order in terms of proto-liberal-capitalist norms would have to be considered a social misdevelopment or a social pathology insofar as these criticisms aimed at eroding the established estate-based order.

Note that I am merely claiming that proto-liberal capitalist norms were, at a particular point in time, not underlying reproductively relevant social institutions. I do not argue that proto-liberal-capitalist norms and practices did not exist (or reject the claim that proto-liberal-capitalist norms and practices could only evolve in response to socio-economic developments that took place at a particular point in history). Nothing I say commits me to the view that we have to conceive of radically critical activities and counter-practices as external to an existing recognition order. My position is perfectly compatible with regarding them as being triggered by historically and contextually specific negative experiences with established, reproductively relevant norm-institution complexes.

What this example demonstrates is that if Critical Theory's aim is to be a force that is truly progressive and unreservedly critical of the status quo, then critical theorists should not adopt a method that considers radical critique and normative revolutions "superfluous" under conditions in which the existing order is, from a backward looking perspective, the most progressive. ${ }^{70}$

Honneth's backward looking perspective cannot explain why it is not a mistake to abandon radical critique and normative revolution because providing an argument to this effect would require to show - and this is something he does not even attempt to do in Freedom's Right - that the current social order is the best possible order that is available at that point in history. However, Honneth's own example of the revolutionary transition from the estate-based to the liberalcapitalist order illustrates that this cannot be inferred from a social order being normatively superior to all its predecessors.

What is more, the example suggests that practices that are radically critical in the sense that they are not grounded in but challenge established, already reproductively relevant norm-institution complexes play a key role in making (potentially superior) alternatives to the existing order available. For these practices tentatively articulate new norms and rehearse corresponding forms of cooperation in the interstices of the existing social order that is to be overcome.

The point of my critique of normative reconstruction is not that there is something wrong with Critical Theory exploring the "neglected potential of already existing institutions." ${ }^{7 \mathrm{I}} \mathrm{I}$ am also not saying that defending existing institutions and promoting forms of gradual progress is always the wrong thing to do. Politically speaking, it might be the best strategy available to us under given historical circumstances: for example, if chances for revolutionary change are miniscule and/or no promising "practical alternatives" have emerged yet and/or existing institutional arrangements are under such a comprehensive attack that it becomes more and more difficult for participants in

${ }^{70}$ Honneth, Freedom's Right, 5 .

${ }^{71}$ Honneth, Freedom's Right, Io. 
these social formations to comprehend the original appeal of these norm-institution complexes. ${ }^{72}$ Furthermore, current social institutions might still provide some or most people with some freedom to critically engage with the status quo, and this freedom might be currently in danger of being further undermined. Being a critical theorist is thus perfectly compatible with being a political realist of sorts who tries to prevent things from getting even worse, or attempts to seize opportunities for further gradual progressive reforms that expand already established freedoms. ${ }^{73} \mathrm{My}$ point is that these sensible political considerations should not be confused with methodological issues. The latter are situated at a different level. For this reason, none of the above mentioned political considerations can be invoked to support the view that Critical Theory should adopt a method that, like the method of normative reconstruction, limits Critical Theory to concern itself exclusively with norms that are already underlying reproductively relevant institutions and the promotion of gradual progress. As a method for Critical Theory, normative reconstruction is therefore too narrow and in need of revision. However, this does not amount to denying the value of the project pursued in Freedom's Right. It is important to reconstruct the norms underlying the existing liberal-capitalist recognition order since we need a better grasp of the norminstitution complexes of which it is composed as well as their potential and the social developments that thwart this potential. All I am saying is that doing this is not enough, given the aspirations of Critical Theory.

\section{Radical critique, normative revolution and the shortcomings of Freedom's Right}

In the final part of this paper, I want to explain why abandoning radical critique and normative revolution not only leads to a stinted account of Critical Theory, but also threatens the cogency of the project Honneth pursues in Freedom's Right. First, I argue that in addition to the reasons outlined in section II, Honneth himself provides us with further reasons for considering the method of normative reconstruction to be incomplete (III.I). Then I explain why normative reconstruction threatens to undermine the explanatory power of Freedom's Right (III.2).

\section{1. The incompleteness of normative reconstruction}

I have demonstrated in section II that Freedom's Right entails no argument to the effect that abandoning radical critique and normative revolution does not render the method of normative reconstruction incomplete. Now I show that Honneth himself gives us (inadvertently) two further reasons for regarding normative reconstruction as incomplete as a method of Critical Theory: first, since this method applies only to the normatively most advanced social formations it cannot be the sole approach to Critical Theory. Otherwise (currently existing) less advanced social formations would fall, in principle, outside the scope of Critical Theory, despite the fact that they also need to be subjected to social criticism.

\footnotetext{
${ }^{2}$ Honneth, Freedom's Right, I96.

73 For an account of Adorno's engagement with politics that could be described as critically realist along these lines, see F. Freyenhagen, “Adorno's Politics," Philosophy \& Social Criticism 40, no. 9 (2014): 867-93.
} 
It could be argued that in such a situation there is not much work left to do for Critical Theory qua theory. However, it might not be unequivocally clear whether a social order is less advanced than others, and theorizing might, thus, be necessary to establish this. Critical Theory could remind us in a systematic fashion of why we consider certain social formations less advanced in comparison with others. Also, Critical Theory might still play a role in dismantling defences of these less advanced social formations. Finally, it is a distinctive feature of Critical Theory that its theoretical aims are linked with the practical aim of emancipation: Critical Theory attempts to explain not only how particular injustices are produced and obfuscated, it also aims to account for how knowledge can be converted into emancipatory practices in concrete historical circumstances. ${ }^{74}$

The second reason to consider normative reconstruction to be incomplete is directly linked to Honneth's account of the dangers associated with social misdevelopments. The form of reconstructive criticism that normative reconstruction makes possible presupposes that norms of social freedom are still underlying those institutions that are relevant for social reproduction. But this very presupposition could be soon (or already has been) undermined by the kind of social misdevelopments to which Honneth draws our attention. ${ }^{75}$ Social misdevelopments might not only bring about an imperfect realization of norms of social freedom, they can also bring about transformations of norm-institution complexes that culminate in the replacement of the norms that are operative in them. In short, Honneth identifies a great danger, namely, that social misdevelopments could eliminate norms of social freedom underlying existing institutions, but he nonetheless adopts a method that falls silent in the very moment this danger materializes. In such a situation normative reconstruction does not even provide us with the resources to continue speaking of a social misdevelopment, since this particular form of internal critique requires that the norms of social freedom are still operative in the institutions in question. ${ }^{76}$ It is this peculiar feature of normative reconstruction that demonstrates its incompleteness and suggests that Honneth fails to draw the lesson from his own analysis.

This is also not a far-fetched scenario. Honneth wonders, for example, if we are already in a situation in which the understanding of the market as a sphere of social freedom has been abandoned as a consequence of processes of the "disorganization of capitalism ... under the pressure of economic globalization," processes of "individualization of responsibility" and the "commercialization" of more and more aspects of social life. ${ }^{77} \mathrm{He}$ contends that as a consequence of these processes "an interpretation of the capitalist market" might have already "come to dominate according to which the market constitutes a sphere of individual rather than social freedom." ${ }^{78}$

\footnotetext{
74 See Honneth, “A Social Pathology of Reason,” 36.

75 See Honneth, Freedom's Right, 213, 222, 252.

${ }^{76}$ See Honneth, Freedom's Right, 250.

77 Honneth, Freedom's Right, $25 \mathrm{I}$.

${ }^{78}$ Honneth, Freedom's Right, 249. A transformation of this kind would also explain "the missing [widespread] outrage" (Honneth, Freedom's Right, 249, also 250-5I) about those developments that (further) undermine the market as a sphere of social freedom.
} 
Implied in such a transformation is a disassociation from norms of social freedom. Therefore the legitimacy of the (post social freedom) market would not be undermined by its failure to realize norms of "social freedom" that once "constituted the basis for the legitimacy of the market."79 For if social misdevelopments have transformed people's normative expectations, then they will no longer expect markets to provide "everybody the opportunity to satisfy their interests in free reciprocity." $8 \circ$ Instead, they now regard the market as a sphere in which individuals can, in competition with others, legitimately pursue the maximization of their own interests without having to take the interest satisfaction of others into consideration. ${ }^{8 \mathrm{I}}$

Honneth does acknowledge that a transformation in the operation and "interpretation of the market ... poses a problem for ... normative reconstruction" since in such a situation "we cannot rely on normative countermoves" because normative expectations have changed. ${ }^{82}$ This is, indeed, a serious problem, but what is more troubling for normative reconstruction as an approach to Critical Theory is that after the transformation has taken place it cannot even explain why the disappearance of normative counter-movements is something that should trouble us. In fact, by treating active participation in a social sphere as a reliable indicator for its being part of the normatively most advanced social formation, Honneth effectively insulates the changed market sphere from critique.

In short, normative reconstruction is incomplete because once norms of social freedom are left behind, the only forms of critique that provide us with a critical perspective are those that invoke norms of social freedom that are no longer, or not yet, underlying existing, reproductively relevant market institutions. Of course, we cannot anticipate the range of negative experiences people will have in a post social freedom market, nor their normative innovations that attempt to capture these experiences, but we can be sure that normative reconstruction will be deaf to these experiences and norms (unless, of course, those championing these radically critical norms have already succeeded in transforming the economic sphere once more in the light of new norms).

Adopting normative reconstruction will therefore make critical theorists passive bystanders in these emancipatory struggles against post social freedom markets, instead of partisan participants in them; and this is not what we should expect from Critical Theory.

\section{2. Capturing the phenomenon: the possibility of disillusionment}

I would like to conclude my discussion of normative reconstruction by highlighting a problem concerning the explanatory power of Honneth's interpretation of processes of deviation and disassociation from established norms of social freedom. Normative reconstruction suggests a particular account of these processes as socially caused misinterpretations of these norms, which,

\footnotetext{
79 Honneth, Freedom's Right, 252.

8० Honneth, Freedom's Right, 250.

${ }^{81}$ Honneth, Freedom's Right.

${ }^{82}$ Honneth, Freedom's Right, 252, also 2 I 3.
} 
in turn, lead to a subsequent failure to be adequately guided by them. ${ }^{83}$ According to Honneth, these processes can even lead to a complete abandonment of, or disassociation from, norms of social freedom. My claim is that Honneth, by way of methodological premises that form part of normative reconstruction, excludes from view alternative interpretations of such processes. To be clear, the problem is not that Honneth integrates substantive hypotheses into his methodology - to do so is inevitable. The problem is that he never adequately scrutinizes these hypotheses. ${ }^{84}$ What Honneth does show is that one can draw on his hypotheses to give an account of these processes of deviation and disassociation that is, at least prima facie, plausible. But this is not enough to justify these methodological assumptions since alternative accounts of these processes are available that are, at least prima facie, equally plausible. What is missing from Freedom's Right is therefore an argument to the effect that Honneth's own explanatory account is the most plausible. In particular, Honneth should not rule out, at the level of methodological premises, the possibility that processes of deviation and disassociation from established norms of social freedom can be an appropriate response, given our experiences over the last couple of centuries with the very norm-institution complexes he reconstructs. In what follows, I outline two alternative disillusionment-driven accounts of these processes.

III. 2. a. The possibility of disillusionment I: a mismatch between norm and institution One possibility Honneth has to at least take into consideration is that we learn over time that the institutions we have are unsuited to realize the very norms we took to be underlying and justifying them.

For example, Honneth might be right that the "conception of social freedom ... has had the greatest amount of influence on the formation of ... modern institutions" such as the "capitalist market." ${ }^{85} \mathrm{He}$ claims that the capitalist market could only establish itself because it was considered to have "social legitimacy," and it was regarded to have "social legitimacy" because it was "understood as the realization" of social freedom. ${ }^{86}$ But the truth of this genetic story is compatible with learning over time that our original views were mistaken. For instance, with time it could become apparent to us that what markets ultimately do is to track supply and demand $;^{87}$ and for systemic reasons, the standard rationale that has to guide investments in capitalist markets is to secure high returns. Market outcomes might sometimes be favourable to those whom we consider to make valuable contributions to society, and we usually get the things we need mediated through market transactions, but this does not change the fact that markets track supply and demand, not social contributions or need. This suggests that what is going on in markets is not internally linked with "the complementary realization of individual aims." 88

\footnotetext{
${ }^{83}$ See Honneth, Freedom's Right, 86, I28.

${ }^{8}$ See Honneth, Freedom's Right, 3 .

${ }^{85}$ Honneth, Freedom's Right, I 24.

86 Honneth, Freedom's Right, I 24 .

87 Honneth, Freedom's Right, I78, 203.

${ }^{88}$ Honneth, Freedom's Right, I92.
} 
Of course, there can be, and have been, interventions in markets (like taxation or consumer cooperatives) that modify market outcomes such that they resemble more what we regard as outcomes that reflect social contributions, or bring about a situation in which more people are able to satisfy their (essential) needs on the market. We can engage in "socially modifying market conditions so that they at least approximate the requirements of social freedom." ${ }_{99}$ But again, conceding this possibility does not turn markets in general, and capitalist markets in particular, into institutions of social freedom. $9^{90}$ Rather, it is because market mechanisms are not intrinsically promoting social freedom that we have to intervene in them to make them more compatible with demands of social freedom.

If the dominant experience with capitalist markets is that they neither track contribution nor promote the reciprocal satisfaction of needs (in a non-accidental fashion), then this experience can give rise to a process of disillusionment that brings in its wake a disassociation from the norm-institution complex "capitalist market." However, contrary to the misdevelopments envisaged by Honneth, this form of disassociation and deviation from norms of social freedom cannot be attributed to a socially caused misunderstanding of the norms underlying the market since this alternative story does not involve any cognitive failures. On the contrary, it is based on a learning process.

The outlined form of disillusionment also puts us in a position to explain the lack of collective resistance against the ongoing "disorganization of capitalism."9I Members of liberal-capitalist societies might no longer conceive of these processes as contingent, externally caused regressions on a trajectory towards an ever more comprehensive realization of a norm of social freedom that is underlying capitalist markets. They might no longer regard the "already existing" normative "potential" as a potential that is intrinsic to the market. ${ }^{92}$ This would explain why recent processes of disorganizing the norm-institution complex "capitalist market" failed to inspire and motivate resistance in the masses - they feel that their normative expectations about social freedom are no longer applicable to the capitalist market but they nonetheless keep participating in it for want of better alternatives, that is, they might simply not know how to structure productive social cooperation such that it realizes social freedom.

My intention was not to present a conclusive vindication of a particular instance of a mismatch between an institution and a norm of social freedom (allegedly underlying it). Rather, my aim was to demonstrate that one cannot not rule out ex ante that our original optimism about an internal link between norms and institutions realizing them, for example, (a robust notion of) social freedom and markets, could turn out to be misguided. Honneth should therefore not make it a methodological premise that any form of deviation and disassociation from norms underlying social institutions (even in the most historically advanced societies) is the result of socially caused failures to adequately understand and act on these

\footnotetext{
${ }^{89}$ Honneth, Freedom's Right, 2 Io; my emphasis.

$9 \circ$ See T. Jütten, "Is the Market a Sphere of Social Freedom?" Critical Horizons, this issue, for a detailed account of why there is no internal link between the market mechanism and a robust conception of social freedom.

${ }^{91}$ Honneth, Freedom's Right, $25 \mathrm{I}$.

92 Honneth, Freedom's Right, Io.
} 
social norms. Being open to historical learning processes also means that we have to be open to the possibility that our original optimism about a fit between a norm and an institution realizing it could have been misplaced. Normative reconstruction blinds Honneth to this possibility, thereby rendering his reconstructive approach to Critical Theory insufficiently self-reflective and self-critical.

\section{2. b. The possibility of disillusionment II: norms losing their grip}

Finally, there is also the possibility that the norms that are underlying existing institutions lose their grip on us because of our experiences with them as realized (not because existing institutions are only imperfectly guided by these norms, or because the institutions that are supposed to realize these norms have been revealed as ill-equipped to do so).

This alternative is again not contemplated in Freedom's Right - and again because of its methodological orientation. Honneth simply takes it for granted that norms of social freedom are undermined by processes "whose source must be sought elsewhere," that is, not in the norms that are "constitutive ... of the respective system of action." 93 Honneth thereby (implicitly) rules out the possibility that established norms of social freedom themselves could be implicated in generating a widespread unwillingness to fight for an ever more perfect realization of these very norms. This amounts to a status quo bias that again traces back to methodological assumptions that form part of normative reconstruction.

Critical Theory needs to be alive to the possibility that our experiences with established norm-institution complexes can transform our aspirations and our evaluations of these norm-institution complexes, even if they "are normatively superior to historically antecedent social ideals."94 Even if one engages, like Honneth in Freedom's Right, in an exercise of giving an account of ethical life or Sittlichkeit, such an account ought to nonetheless make room for experiences of negativity that could fuel normative revolutions. Honneth renders his account of Sittlichkeit in Freedom's Right deaf to negative experiences with established norms by disregarding this possibility, that is, experiences of negativity that cannot be adequately addressed by coming up with a more adequate interpretation and/or comprehensive realization of established norms. Critical Theory should not adopt a version of internal critique that seals Critical Theory off from the emancipatory potential such experiences of negativity engender. ${ }^{95}$

Taking into consideration the possibility that established norms can lose their grip on us also provides us with another way of accounting for the absence of widespread protests against recent social developments that undermine norms of social freedom. We might even invoke this possibility to make sense of the particular form that some recent protest movements took. Think, for instance, of the Occupy movement. One feature that became the subject of some speculation

\footnotetext{
93 Honneth, Freedom's Right, I 29.

${ }_{94}$ Honneth, Freedom's Right, 5, also 63-4. Honneth comes close to acknowledge this in his "The Normativity of Ethical Life."

${ }_{95}$ For a helpful survey of the emancipatory potential of negative social experiences and the challenges a political philosophy of social suffering faces, see E. Renault, "The Political Philosophy of Social Suffering," in New Waves In Political Philosophy, ed. B. de Bruin and C. Zurn (London: Palgrave Macmillan, 2009), I $58-76$.
} 
and debate was its peculiar silence. ${ }^{96}$ This silence could be interpreted as an expression of an unwillingness on the part of the protesters to make claims in terms of already institutionalized norms of social freedom, which, in turn, could be explained by these norms having lost their appeal: they no longer capture the imagination and aims of those who live with them. This feature renders Occupy strikingly different from, for instance, the Civil Rights movement. The latter movement was about ending a regime of interpreting and implementing established norms in a terribly discriminatory way. Instead of making demands of this kind, the Occupy protests took the form of reclaiming public squares to exhibit the felt need to come together, so that people from all walks of life can express and attempt to make sense of their negative social experiences, cooperatively search for a language to express their dissatisfactions with established norm-institution complexes and explore, in practice, new forms of norm-guided cooperation.

Consider, for instance, the sphere of productive social cooperation. Honneth argues that the norm regulating this sphere requires that social esteem is tracking one's contributions to society. The problem with this achievement principle is not only, as Honneth suggests, that it has never been adequately interpreted and implemented. From experience we know that the achievement principle fuels a whole range of problematic social dynamics. These dynamics could lead people to reconsider whether we should even strive for a more perfect realization of this norm, or abandon it in favour of a different norm that could regulate productive social cooperation. For example, the achievement principle gives rise to a comparative and competitive attitude that leads people to equate "doing well" with "doing better" than others. ${ }^{97}$ This desire to do better than others is a constant source of social conflict because "my desire to be recognized as superior to you stands ... in conflict with your similar desire with regards to me. ${ }^{98}$ In this way, the achievement principle contributes to creating unhappiness and social suffering, first, because we feel a constant pressure to outperform others, and second, because the very nature of the desire to be superior precludes collective satisfaction. What is more, this desire has a tendency to produce "callous disregard for the suffering of others" because doing better by outperforming is only one way of satisfying the desire to be recognized as superior to others. The other option is to push those down with whom one compares oneself. ${ }^{99}$ The achievement principle therefore promotes (indirectly) a disposition to rejoice at the lowering of the status of others. ${ }^{\text {Ioo }}$

This brief discussion of the achievement principles illustrates that one cannot rule out ex ante, as Honneth does in Freedom's Right, that negative experiences with established norms of social freedom can bring about a situation in which these norms lose their appeal. This can happen even if alternatives to established norm-institution

\footnotetext{
${ }^{6}$ See, for example, S. Žižek, "The Violent Silence of a New Beginning," (20II): accessed 5 July 20I4, http:// inthesetimes.com/article/I 2 I 88 /the_violent_silence_of_a_new_beginning

97 F. Neuhouser, Rousseau's Theodicy of Self-Love: Evil, Rationality, and the Drive for Recognition (Oxford: Oxford University Press, 2008), 74; see also J.-J. Rousseau, "Discourse on the Origin and Foundations of Inequality among Men or Second Discourse," in The Discourses and Other Early Political Writings, ed. and trans. V. Gourevich (Cambridge: Cambridge University Press, I997), III-23I.

${ }_{98}^{8}$ Neuhouser, Rousseau's Theodicy of Self-Love, 75 .

99 Neuhouser, Rousseau's Theodicy of Self-Love, 76.

${ }^{100}$ Rousseau, "Discourse," I7I.
} 
complexes are not yet in view and most people still participate in existing social institutions. ${ }^{\text {IOI }}$ Both types of disillusionment-driven disassociations from established norms of social freedom - that is, disassociations based on an appreciation of a mismatch between norms and the institutions that are supposed to realize them, on the one hand, and disassociations that are motivated by negative experiences with the realization of norms, on the other hand - can be a social reality even if people might still comply with existing norms for want of better alternatives. ${ }^{\text {I02 }}$

These alternative accounts of processes of deviation and disassociation from norms that are underlying existing social institutions support a more general point: substantive explanatory matters cannot be settled at the level of methodological premises. It also has become apparent why Critical Theory requires a method that allows it to be alive to the whole range of negative experiences people can have. Finally, critical theorists should participate in, and reflect on, the attempts to express these negative experiences in normative language, no matter whether these norms are not yet, or no longer, operative in social institutions that are relevant for the reproduction of society; ${ }^{\mathrm{IO} 3}$ inter alia because these (radically) critical practices are essential for paving the way for (potentially progressive) normative revolutions, just as the explorations of the notion of human equality and the idea of a contribution-tracking economic cooperation in the period before the French Revolution did. Unfortunately, this openness for radical critique and normative revolutions is lost in Freedom's Right. As a consequence of adopting normative reconstruction, Honneth marginalizes forms of negative experience with established norms, radical critique and social movements striving for normative revolutions simply because they are non-reformist in character. For instance, those parts of the "labour movement" that were not in any obvious way "dealing with the principle of the reformability" of the capitalist market, but aimed for "an entirely different model" are sidelined from his "reconstruction" for the simple reason that they are not pushing "for internal corrections to the [capitalist] market." I04

\section{Conclusion}

In this paper, I read (the middle period) Honneth against (the latest) Honneth in order to demonstrate that the method of normative reconstruction, as conceived in Freedom's Right, is not only ill-suited for taking Critical Theory forward, it actually amounts to a step backwards compared to Honneth's earlier works. The upshot of my argument is that a defensible approach to Critical Theory has to be open to forms of radical critique and normative revolution, and that Freedom's Right contains no resources to account for why abandoning radical critique and revolutionary progress does not amount to a shortcoming.

\footnotetext{
ror See Honneth, Freedom's Right, I96.

${ }^{102}$ See G. Packer, The Unwinding: An Inner History of the New America (London: faber \& faber, 2013); R. Raatzsch, "On the Very Notion of Compliance With some Help from William James" (unpublished manuscript).

${ }^{103}$ Such experiences of negativity should, however, not be treated simply as "spontaneous and authentic feelings with inherent moral status" that can be exempt from critical scrutiny since "all experience is mediated through a web of potentially distorting symbolic relations" (L. McNay, "The Trouble with Recognition: Subjectivity, Suffering, and Agency," Sociological Theory 26, no. 3 (2008): 27I-96, here 278).

${ }^{104}$ Honneth, Freedom's Right, 2 Iо.
} 
I also provide additional reasons for considering the method of normative reconstruction to be incomplete: first, its premises imply that it only has a limited scope of application, and second, it falls silent in the very moment those dangers associated with social misdevelopments fully materialize. Finally, I explain why the explanatory power of Freedom's Right is dubious because the methodological premises that form part of normative reconstruction lead Honneth to ignore relevant alternative explanations of processes of deviation and disassociation from norms of social freedom, which he characterizes as social misdevelopments.

The main upshot of my argument is that Honneth needs to revise the method of normative reconstruction such that it becomes open (again) to the possibility of normative revolution and radical critique. In doing so, Honneth should distinguish between three different forms such revolutions can take:

(i) The possibility of a mismatch between norms of social freedom and the institutions that are supposed to realize them shows that we have to take seriously pure institutional revolutions. In such a revolution we hold on to the norm in question but institutionally innovate to establish an institution that is actually (or better) suited to realize this norm. Honneth should be sympathetic to pure institutional revolutions since one of the problems he identifies with Hegel's account of Sittlichkeit is "overinstitutionalization." ${ }^{\circ 5}$ For Honneth, the critical potential of Hegel's reconstructive approach is undermined because he equates a particular norm or form of recognition "with the institutional complexes typical of" his own "time." ${ }^{\text {Io6 }}$ We have no reason to rule out ex ante the possibility that the same norm or form of recognition could be better realized by different social institutions.

(ii) A revolution of particular norms of social freedom does involve a change of norms. Honneth should take this possibility seriously since one cannot infer from the fact that particular norms of social freedom are underlying existing institutions that these are the best norms of social freedom. For instance, we cannot conclude from the achievement principle's being operative in the sphere of productive social cooperation that there are no better norms that could guide this sphere such that it provides everybody with an "opportunity to satisfy their interests in free reciprocity." 107

(iii) Finally, the most fundamental form of normative revolution would involve the byper value of (social) freedom itself. For Honneth, this value has placed "all modern ethical ideals" under its "spell," leaving us with no other "independent, stand-alone alternative." I08 In any case, even if Honneth is right that individual self-realization or autonomy has become

${ }^{105}$ A. Honneth, The Pathologies of Individual Freedom: Hegel's Social Theory, trans. L. Loeb (Princeton, NJ: Princeton University Press, 2010), 63-80.

${ }^{106}$ Honneth, "Redistribution as Recognition," I 45. One of Honneth's examples is Hegel's failure to appreciate that the norm of love can be realized both within and outside the bourgeois family, for instance, in informal relationships between friends. See Honneth, The Pathologies of Individual Freedom, 67-70.

107 Honneth, Freedom's Right, 250.

${ }^{108}$ Honneth, Freedom's Right, I 5. 
irresistible for us moderns, he is wrong to infer from this that promoting pure institutional revolutions and revolutions of particular norms of social freedom can no longer be the task of Critical Theory.

\section{Acknowledgements}

For helpful discussions and comments on earlier versions of this article, I am grateful to Manuel Dries, Fabian Freyenhagen, Steve Gormley, Axel Honneth, Timo Jütten, David McNeill, Joseph Shear and two reviewers for this journal.

\section{References}

Allen, A. The End of Progress: De-Colonizing Critical Theory (unpublished manuscript).

Freyenhagen, F. “Adorno's Politics.” Philosophy \& Social Criticism 40 (2014): 867-893.

Freyenhagen, F. "Honneth on Social Pathologies: A Critique.” Critical Horizons I6 (20I 5): I3 I-52.

Geuss, R. The Idea of a Critical Theory: Habermas \& the Frankfurt School. Cambridge: Cambridge University Press, I98I.

Geuss, R. Philosophy and Real Politics. Princeton, NJ: Princeton University Press 2008.

Habermas, J. Between Facts and Norms: Contributions to a Discourse Theory of Law and Democracy, translated by W. Rehg. Cambridge: Polity, I996.

Honneth, A. "Grounding Recognition: A Rejoinder to Critical Questions.” Inquiry 45 (2002): 499-5I9.

Honneth, A. "Redistribution as Recognition: A Response to Nancy Fraser." In Redistribution or Recognition? A Political-Philosophical Exchange, N. Fraser and A. Honneth, I I0-97. New York: Verso, 2003.

Honneth, A. "Pathologies of the Social: The Past and Present of Social Philosophy." Disrespect: The Normative Foundations of Critical Theory, 3-48. Cambridge: Polity, 2007.

Honneth, A. “A Social Pathology of Reason: On the Intellectual Legacy of Critical Theory.” In his Pathologies of Reason: On the Legacy of Critical Theory, translated by J. Ingram, IO-42. New York, NJ: Columbia University Press, 2009.

Honneth, A. “The Irreducibility of Progress: Kant's Account of the Relationship between Morality and History." Pathologies of Reason, I-I 8. New York: Columbia University Press, 2009.

Honneth, A. The Pathologies of Individual Freedom: Hegel's Social Theory. translated by L. Loeb. Princeton, NJ: Princeton University Press, 2010.

Honneth, A. Freedom's Right: The Social Foundations of Democratic Life. translated by J. Ganahl. Cambridge: Polity, 20I4.

Honneth, A. "The Normativity of Ethical Life.” Philosophy and Social Criticism (forthcoming).

Jütten, T. "Is the Market a Sphere of Social Freedom?" Critical Horizons I6 (201 5): I87-203.

McNay, L. "The Trouble with Recognition: Subjectivity, Redistribution as Recognition: A Response to Nancy Fraser." Sociological Theory 26 (2008): 271-96.

Neuhouser, F. Rousseau's Theodicy of Self-Love: Evil, Rationality and the Drive for Recognition. Oxford: Oxford University Press, 2008.

Packer, G. The Unwinding: An Inner History of the New America. London: faber \& faber, 2013.

Raatzsch, R. “On the Very Notion of Compliance With some Help from William James” (unpublished manuscript).

Renault, E. "The Political Philosophy of Social Suffering." In New Waves In Political Philosophy, edited by B. de Bruin and C. Zurn, I 5-76. London: Palgrave Macmillan, 2009.

Rousseau, J.-J. "Discourse on the Origin and Foundations of Inequality among Men or Second Discourse." The Discourses and Other Early Political Writings, edited and translated by V. Gourevich, III-23I. Cambridge: Cambridge University Press, I997.

Williams, B. In the Beginning Was the Deed: Realism and Moralism in Political Argument. Princeton, NJ: Princeton University Press, 2005. 
Willig, R. "Grammatology of Modern Recognition Orders: An Interview with Axel Honneth.” Distinktion I3 (2OI2): I45-49.

Žižek, S. "The Violent Silence of a New Beginning.” (20II). Accessed 5 July 20I4. http://inthesetimes.com/ article/I 2 I 88/the_violent_silence_of_a_new_beginning.

\section{Notes on contributor}

Jörg Schaub is a lecturer in philosophy at the University of Essex, UK. His current research focuses on the methodological foundations of contemporary political philosophy, aesthetics and politics, critical theory, political realism, and social pathologies. He is author of the monograph Gerechtigkeit als Versöhnung. John Rawls' Politischer Liberalismus and has articles published in Deutsche Zeitschrift für Philosophie, Zeitschrift für Politische Theorie, Leviathan and Res Publica.

Correspondence to: jschaub@essex.ac.uk. 